\title{
A Terapia Ocupacional na prática de grupos e oficinas terapêuticas com pacientes de saúde mental ${ }^{1}$
}

\author{
Janaina Bussola Montrezor \\ Terapeuta ocupacional do Pólo de Atenção Intensiva em Saúde Mental - Cruzada Bandeirante São Camilo \\ de Assistência Médico Social, Santos, SP, Brasil, especialista em Administração Hospitalar pelo Centro \\ Universitário São Camilo - USC, Terapeuta ocupacional de projeto acadêmico da Universidade Federal de \\ São Paulo - UNIFESP, Santos, SP, Brasil
}

\begin{abstract}
Resumo: Objetivou-se demonstrar a efetividade da Terapia Ocupacional junto à pacientes portadores de transtornos mentais através de grupos terapêuticos em uma unidade de internação intensiva. Os grupos terapêuticos realizados foram: grupos de reflexão, operativos, oficinas de desenho e de artes. Participaram do estudo 280 pacientes (46,07\% com CID F20-29, 23,57\% com CID F30-39 e 14,28\% com CID F19). Do total de pacientes ( $\mathrm{n}=280), 54,00 \%$ participaram dos grupos operativos, $52,85 \%$, dos grupos de reflexão, $46,80 \%$, das oficinas de desenho e $45,70 \%$, das oficinas de artes. Em todos os grupos a participação do grupo CID F20-29 foi maior (49,25\% nos grupos de reflexão, 54,00\% nos grupos operativos, $51,00 \%$ nas oficinas de desenho e $66,00 \%$ nas oficinas de artes); seguido do grupo CID F30-39, com 24,25\% nos grupos de reflexão, 27,00\% nos operativos e 22,00\% nas oficinas de desenho; nas oficinas de artes, o grupo CID F19 se destacou. Os pacientes com esquizofrenia, psicoses, transtornos bipolares etc. (CID F20-29 e F30-39) apresentaram maior participação em grupos nos quais foram discutidos conteúdos como alegria, raiva, medo etc. Já o grupo CID F19 apresentou maior participação nas oficinas de artes, fato que pode ser explicado pelo perfil desses pacientes, pois muitos já estiveram em presídios e/ou internados em hospitais de longa permanência, onde aprenderam a exercer atividades manuais para posterior sobrevivência na sociedade. Desse modo, conclui-se que os grupos terapêuticos são eficazes no tratamento de pacientes de saúde mental, uma vez que contribuem para a alta hospitalar e melhoram o quadro clínico do paciente.
\end{abstract}

Palavras-chave: Terapia Ocupacional, Saúde Mental, Grupos Terapêuticos.

\section{Occupational Therapy in the practice of therapeutic groups and workshops with mental health patients}

\begin{abstract}
In this study, we aimed to demonstrate the effectiveness of occupational therapy to patients with mental disorders through therapy groups in an intensive inpatient unit. The following treatment groups were performed: focus groups, operative groups, drawing workshops, and arts workshops. The study included 280 patients $(46.07 \%$ with ICD F20-29, 23.57\% with ICD F30-39, and 14.28\% with ICD F19). Of all the patients studied ( $\mathrm{n}=280), 54.00 \%$ participated in the operative groups, $52.85 \%$ in the focus groups, $46.80 \%$ in the drawing workshops, and $45.70 \%$ in the art workshops. In all groups, the participation of the ICD F20-29 group was higher (focus group with $49.25 \%, 54.00 \%$ in the operative group, $51.00 \%$ in the workshops of drawing, and $66.00 \%$ in art workshops), followed by the ICD F30-39 group with $24.25 \%$ in the focus group, $27.00 \%$ in the operative group, and $22.00 \%$ in the drawing workshops; the ICD F19 group stood out in the arts workshops. Patients with schizophrenia, psychoses, bipolar disorders, among others (ICD F20-20 and ICD F30-39) were the most active in the therapeutic groups, which discussed contents such as joy, anger, fear, thoughts of death, etc. The ICD F19 group presented the greatest participation in the art workshops, a fact that can be explained by the profile of these patients, because many have been in prison and/or admitted to long-stays in hospitals where they learned to perform manual tasks for subsequent survival in society. We concluded that therapeutic groups are effective in treating mental health patients because they contribute to hospital discharge and improve patients' conditions.
\end{abstract}

Keywords: Occupational Therapy, Mental Health, Therapeutic Groups.

Autor para correspondência: Janaina Bussola Montrezor, Pólo de Atenção Intensiva em Saúde Mental da Baixada Santista (PAI), Av. Ibitinga, 965, Jardim Aeroporto, CEP 15991-205, Matão, SP, Brasil, e-mail: janamontrezor@gmail.com

Recebido em 18/11/2011; $1^{\text {a }}$ Revisão em 11/10/2012; Aceito em 17/12/2012. 


\section{Introdução}

A Terapia Ocupacional no campo da saúde mental apresenta diferentes estratégias de intervenção, entre elas as oficinas e grupos terapêuticos, que constituem um dispositivo de tratamento bastante utilizado na clínica da Terapia Ocupacional (BARATA; COCENAS; KEBBE, 2010).

Dentro dos grupos terapêuticos existem diversos tipos de grupos que não são específicos da Terapia Ocupacional, entretanto seus princípios podem ser utilizados dentro do processo terapêutico ocupacional, desde que o profissional possua as habilidades necessárias (CUNHA; SANTOS, 2009). De acordo com Kebbe, Santos e Cocenas (2010), um dos princípios norteadores da prática do terapeuta ocupacional com grupos de atividades é a ideia de que o fazer junto tem efeito terapêutico.

Maximino (2001) traz a ideia de grupo como sendo um conjunto de pessoas reunidas com o propósito de "fazer atividades" mediante açôes e uso de materiais, na confecçáo de artesanatos, em artes plásticas, desenho, teatro, entre outras. A autora ainda sugere que a escolha da atividade e sua execução variam conforme o perfil e as necessidades de cada grupo e, de acordo com a orientação teóricometodológica do terapeuta ocupacional. De acordo com Hagedorn (2007), os grupos de atividades da Terapia Ocupacional são marcados pelo envolvimento simultâneo de clientes na realização de uma ou mais tarefas ou atividades produtivas, criativas ou sociais, sempre com um propósito terapêutico específico estabelecido pelo terapeuta ocupacional.

Para Ballarin (2003), um grupo de atividades em Terapia Ocupacional é definido como um espaço onde os pacientes se reúnem na presença do terapeuta ocupacional para vivenciar experiências relacionadas ao fazer como, por exemplo: pintar, passear, desenhar, modelar, dançar, fazer compras, costurar, entre outras. A autora ainda acrescenta que o grupo pode funcionar como uma caixa de ressonância, ampliando as possibilidades de intervenção e tornando-se para seus integrantes um ambiente confiável e facilitador da exploração do mundo, assumindo entáo uma função de espaço potencial.

Os grupos, em Terapia Ocupacional, objetivam o tratamento e ofertam vivências aos seus participantes através do "fazer junto", como o compartilhamento de experiências, a interação social, a comunicação verbal e não verbal e a exposição de sentimentos e conteúdos internos (BALLARIN, 2003; NASCIMENTO et al., 2007). Liebmann (2000), através de pesquisa feita com terapeutas ocupacionais que utilizavam a abordagem grupal, aponta alguns objetivos dos grupos terapêuticos, como: criatividade e espontaneidade, construção da autoconfiança, percepçáo do seu próprio potencial, aumento de autonomia e motivaçáo pessoal, desenvolvimento individual, liberdade para tomar decisóes, expressão de sentimentos, emoçóes e conflitos, trabalhar com a imaginação e o inconsciente, reflexão, relaxamento, entre outros.

O local de execução das atividades desses grupos terapêuticos é chamado de setting terapêutico e é característico da Terapia Ocupacional. Para Villares (1998), o setting terapêutico é composto desde a sala de Terapia Ocupacional (caracterizada por um espaço em que convivem diversos materiais e trabalhos, sendo utilizados ou não), até o jardim, corredores, ruas e os lugares coletivos. O setting terapêutico é chamado por Azevedo e Dimenstein (2008) de "clínica em movimento" constituída por diálogos, passeios, paisagens, entre outros elementos que favorecem a passagem dos sentidos, o rearranjo de fragmentos, a formação de figuras, mesmo que para isso outras tenham que ser desconstruídas.

Para Zimerman (2000), a função mais nobre do setting terapêutico consiste na criação de um novo espaço onde o analisando terá a oportunidade de reexperimentar com o seu analista a vivência de antigas e marcantes experiências emocionais conflituosas que foram mal compreendidas, atendidas e significadas pelos pais no passado e, por conseguinte, mal solucionadas pela criança de ontem, que habita a mente do paciente adulto de hoje. Ballarin (2003) acrescenta ainda a figura do terapeuta como constituinte do espaço terapêutico. Para Samea (2008), o espaço grupal possibilita o contato e o reconhecimento do próprio fazer, seus limites e facilidades, a observação do fazer do outro, a percepçáo de semelhanças e contrastes e a potencialização do fazer junto.

Tratando-se de pacientes portadores de transtornos mentais, Cunha e Santos (2009) relatam que a formaçáo de grupos terapêuticos com o intuito de tratar esses pacientes é vantajosa, já que a constituição de um grupo é considerada, por si só, um recurso terapêutico e a terapia realizada através dos grupos possibilita trabalhar objetivos distintos da terapia individual, alcançando, consequentemente, resultados diferentes. Hagedorn (2007) aponta que o trabalho em grupo é considerado uma ferramenta eficaz no tratamento do cliente com transtorno mental, pois a dificuldade de relacionamento e o embotamento afetivo característicos desses pacientes podem ser melhor superados a partir da abordagem na atividade grupal.

Os grupos de atividades e as oficinas terapêuticas, para Mendonça (2005), constituem-se em novas 
práticas de inserção social nos hospitais psiquiátricos. De acordo com o autor, além do tratamento clínico, que é fundamental, o paciente necessita de seu direito de criar, opinar, escolher, relacionar-se, entre outros, conquistados através dos grupos de atividades.

Bezerra e Oliveira (2002) relatam que, partindo-se do princípio de que o ato criativo (presente nos grupos terapêuticos) é desencadeado por um estado motivacional de insatisfaçáo ou desacordo interno, é possível perceber que a expressáo proporciona um alívio que, além de prazeroso, restabelece o equilíbrio emocional do paciente. Scherer e Scherer (2001) afirmam que através dos grupos de atividades é possível observar-se melhoras na socialização dos pacientes, nos relacionamentos grupais, na aceitação da doença. Os pacientes, quando aceitam a doença e passam a buscar o tratamento, querem voltar ao trabalho, procuram atividades que os façam sentirem-se úteis, demonstram a vontade de produzir e vencer a doença através da ocupação e mostram a necessidade de aprender alguma atividade artesanal.

De acordo com Samea (2008), há pouca literatura brasileira referente à utilização de grupos e oficinas terapêuticas na área de saúde mental; entretanto, os grupos têm se revelado, cada vez mais, importante dispositivos de investigação e intervenção na prática terapêutica. A autora relata ainda que, durante os grupos terapêuticos, vários sujeitos estão juntos, compartilhando tempo, espaço e um fazer através das interaçóes; múltiplos podem ser os conteúdos gerados pelos encontros, o que é manifesto vem carregado de significaçôes que, no contato com o outro, podem adquirir ainda novos significados, explicitando diferenças e semelhanças, traços culturais distintos, marcas das histórias e desejos. De modo geral, os grupos de atividades e oficinas terapêuticas são vistos como instrumento de enriquecimento, de valorização da expressão, de descoberta e ampliação de possibilidades individuais e de acesso a bens culturais (MENDONÇA, 2005).

Sendo assim, o objetivo deste artigo foi demonstrar a efetividade da clínica da Terapia Ocupacional (no âmbito da Gestão Hospitalar) na alta hospitalar de pacientes portadores de transtornos mentais através de grupos terapêuticos em uma instituição de internação intensiva em saúde mental.

\section{Procedimentos metodológicos}

Este estudo caracterizou-se como estudo comparativo de caso, tendo seguido uma abordagem quantitativa, realizada em uma instituição de internação intensiva em saúde mental da cidade de Santos, SP, no período de julho a dezembro de 2010.
O critério de seleçáo do local de realizaçáo foi o de a instituição não ser considerada um hospital-dia, ou seja, os pacientes permaneciam internados na instituição por um determinado período de tempo e participavam de grupos e atividades terapêuticas como parte do processo de tratamento. Além disso, a instituição era um local relativamente novo e apresentava uma proposta nova de tratamento ao doente mental (na época do estudo, o local funcionava há apenas seis meses).

Inicialmente foram escolhidos alguns grupos terapêuticos realizados pelo setor de Terapia Ocupacional da instituição, sendo o critério de seleção a diversidade das propostas de cada grupo terapêutico (todos os grupos foram classificados como heterogêneos e abertos). Selecionou-se, então, quatro categorias de grupos terapêuticos, que foram: Grupo de reflexão, Grupo operativo, Oficina de desenho e Oficina de artes.

A participação dos pacientes nos grupos terapêuticos foi quantificada e analisada, comparando-se o total de altas desses mesmos pacientes e o tempo de sua internação com o total de reinternaçóes ocorridas no período do estudo. Os dados foram tabulados e analisados por uma das terapeutas ocupacionais da instituição (pesquisadora deste estudo de caso).

Para a coleta de dados referentes ao processo de participaçáo dos pacientes nos grupos terapêuticos foi utilizada a planilha de dados do programa Excel for Windows (versão 2003), tabulando-se dados como: total de pacientes internados no período, quantidade de pacientes participantes em cada grupo terapêutico, período de internaçáo de cada paciente e o diagnóstico de cada um, de acordo com a Classificação Internacional de Doenças e Problemas relacionados à Saúde - CID10 (ORGANIZAÇÃO..., 2013). Essa planilha foi preenchida pelas terapeutas ocupacionais da instituição após a realização de cada sessão de grupo terapêutico, sendo também um documento de prestação de contas do setor de Terapia Ocupacional para a instituição e de autoavaliação do próprio setor quanto às suas atividades profissionais. Os dados tabulados só foram utilizados para este estudo de caso após a autorização da direção administrativa da instituição.

Para comparação com os dados numéricos coletados no processo de participaçáo dos pacientes nos grupos terapêuticos, os dados referentes a total de altas hospitalares e total de reinternaçóes na instituição no período do estudo foram solicitados à diretoria administrativa da instituição, que também autorizou a realização deste estudo.

Como complemento do estudo, foi realizada uma revisão bibliográfica sobre grupos terapêuticos, alta 
hospitalar, saúde mental, instituiçóes psiquiátricas, terapia ocupacional, entre outros assuntos. Constatou-se carência de publicaçóes sobre Terapia Ocupacional no âmbito da Gestão Hospitalar, por exemplo: a contribuição do trabalho da Terapia Ocupacional para a alta hospitalar em unidades em que o paciente se mantém internado por um determinado período de tempo; o benefício da atividade na "reconstruçáo" do paciente dentro do hospital, entre outras.

\section{Resultados e discussão}

\subsection{A instituição}

A unidade de internação intensiva em saúde mental referida neste estudo localizava-se na cidade de Santos, SP, dentro de um hospital geral. A unidade contava com gerência privada (Organizaçáo Social Cruzada Bandeirante São Camilo de Assistência Médico Hospitalar), porém atendia somente usuários do Sistema Único de Saúde (SUS). Sua inauguração oficial ocorreu no dia 25 de outubro de 2010, porém a Organização Social (OSS) Cruzada Bandeirante Sáo Camilo assumiu a unidade no dia 6 de julho de 2009. O início das atividades assistenciais ocorreu no mês de janeiro do ano de 2010, depois de uma grande reforma em toda a unidade. A unidade de internação intensiva em saúde mental tinha por objetivo suprir a necessidade de um serviço de internação breve a indivíduos portadores de transtornos mentais severos e persistentes em quadro agudo, com prioridade para adolescentes e portadores de doenças clínicas como esquizofrenia e outros transtornos psicóticos, transtorno bipolar do humor e depressão unipolar grave, e transtornos mentais orgânicos com manifestaçóes comportamentais graves.

A instituição tinha capacidade máxima de 30 leitos (sem restrição quanto a gênero) e mesmo após a privatização (tornou-se uma organização social), continuou como patrimônio público sob a responsabilidade do estado, atendendo os nove municípios da Baixada Santista (Santos, São Vicente, Cubatăo, Guarujá, Praia Grande, Peruíbe, Mongaguá, Itanhaém e Bertioga), sendo 100\% do atendimento SUS. O tempo de permanência dos usuários no serviço era de 15 a 20 dias (dependendo do quadro clínico e da demanda de internação de cada um) e eram oferecidas, diariamente, diferentes estratégias terapêuticas, efetivadas pela equipe interdisciplinar.

Para a internação na unidade, era necessário os usuários terem encaminhamento de alguma unidade de saúde (NAPS, CAPS, UBSs, prontos-socorros etc.) de seu município de origem e esse encaminhamento era direcionado para a Central de Vagas da DRS IV do estado de Sáo Paulo, que respondia pela liberação ou negação do pedido de internação. A instituição somente recebia e acolhia os usuários após autorização dessa central de vagas.

Seu projeto terapêutico objetivava, primariamente, diagnosticar adequadamente os diversos transtornos mentais, introduzir os tratamentos mais adequados e, de modo individualizado e humanizado para cada paciente, buscar a remissão do quadro psiquiátrico agudo do paciente, a reabilitação psicossocial, com abordagem e reestruturaçáo do ambiente familiar. Para tanto, contava com uma equipe interdisciplinar formada por médicos psiquiatras, médico clínico, terapeutas ocupacionais, psicólogos, assistentes sociais, educador físico, nutricionista, farmacêutico e toda a equipe de enfermagem (técnicos e enfermeiros).

Essa unidade de internação intensiva em saúde mental acabou se tornando referência, na Baixada Santista, no atendimento aos portadores de transtornos mentais.

\subsection{Os grupos e oficinas terapêuticas}

Por se tratar de uma unidade de internação relativamente nova, o setor de Terapia Ocupacional foi "construído" e "planejado" pelas terapeutas ocupacionais contratadas da unidade (as duas primeiras terapeutas ocupacionais contratadas no começo de 2010, recém-formadas da primeira turma de Terapia Ocupacional da Universidade Federal de Sáo Paulo - UNIFESP, continuavam atuando na instituição). Os grupos e oficinas terapêuticas foram estabelecidos pelas terapeutas ocupacionais da equipe interdisciplinar, valendo-se de suas experiências em estágios profissionalizantes na área de saúde mental, e tornaram-se parte integrante de outras abordagens terapêutico-ocupacionais da instituição. As terapeutas ocupacionais se propuseram a criar um serviço de excelência e humanizado para tratamento de portadores de transtornos mentais.

Como norma da instituição e por se tratar de um programa novo de Terapia Ocupacional em implantaçáo, o setor de Terapia Ocupacional responsabilizou-se pela realização das análises dos grupos terapêuticos após cada sessão, para acompanhar a progressão e analisar os possíveis déficits da dinâmica em curso e realizar um resumo das avaliações de cada grupo, passado para a equipe interdisciplinar através do sistema operacional de computadores (PR). Nesse sistema operacional, que regia todos os computadores da instituição, os profissionais digitavam a evolução de cada paciente internado (evolução médicas, evolução da enfermagem e evolução da equipe interdisciplinar, 
composta por terapeutas ocupacionais, psicólogos, assistentes sociais, educador físico e nutricionista); depois de feitas, todas essas evoluçóes eram impressas e anexadas as prontuário de cada paciente. Em um local específico desse sistema operacional, as terapeutas ocupacionais descreveram o andamento e as percepçôes pessoais dos grupos terapêuticos, que eram levadas para as reunióes de equipe e para as discussóes de caso, além de servirem como "parâmetro" para as avaliaçôes de cada grupo terapêutico.

Os grupos terapêuticos fizeram parte do processo de tratamento do paciente, já que o mesmo contava com o tratamento medicamentoso e com demais grupos de outros profissionais, como o grupo psicoterapêutico do setor de psicologia, a oficina de culinária do setor de nutrição, grupo de jogos do setor de educação física, entre outros. Durante o período de internação, os pacientes tinham total liberdade para participar ou não dos grupos e atividades propostas, entretanto, as terapeutas ocupacionais, após realizarem o primeiro contato com os pacientes, os avisavam da rotina das atividades terapêuticas e explicavam a sua importância; em um mural no refeitório/pátio de uso comunitário dos pacientes era fixado o cronograma semanal com a programação das atividades de toda a equipe interdisciplinar.

De modo geral, os grupos terapêuticos tinham por objetivo identificar, por meio do fazer (atividades), as dificuldades e os desafios de cada paciente, buscando a resolução dessas dificuldades e fazendo com que o paciente conseguisse lidar mais efetivamente com conflitos pessoais vividos em outros grupos sociais (como a família, entre os amigos, no ambiente de trabalho, entre outros). Também tinham por objetivo "preparar" os pacientes para a realidade e o convívio em sociedade (como a volta ao trabalho ou à escola).

Os grupos terapêuticos do setor de Terapia Ocupacional foram realizados por duas terapeutas ocupacionais e os grupos selecionados para as análises, de acordo com os critérios descritos em Procedimentos metodológicos, foram: Grupo de reflexão, Grupo operativo, Oficina de desenho e Oficina de artes.

No Grupo de reflexão realizavam-se atividades que remetiam à reflexão sobre sentimentos como angústias, medos, inseguranças, desafios, sonhos, entre outros, e sobre o próprio estado de saúde do paciente, o conhecimento e a interação com a própria doença e o autoconhecimento. Nesse grupo foram utilizadas atividades de escrita, com desenhos, fotos, recortes de jornais e revistas, sempre seguindo um tema a ser discutido; cada paciente possuía, também, um caderno (espécie de diário) onde escrevia como estava sendo o período de internação, suas angústias, medos e os planos futuros, para serem discutidos com os demais pacientes e com as terapeutas ocupacionais.

No Grupo operativo a atividade centrava-se em tarefas: cada paciente tinha uma função específica e dependia, também, da função do outro; as atividades eram em processos. Nesse grupo eram trabalhados, por exemplo, a plantação e, depois, manutenção da horta e do jardim da unidade; sendo cada paciente responsável por uma função dentro de uma determinada atividade.

No Grupo oficina de desenho utilizavam-se técnicas variadas de desenho como, por exemplo: desenho com carvão vegetal, com aquarela, desenho continuado, desenho com materiais recicláveis, entre outros; algumas vezes direcionava-se esse grupo para um tema específico a desenhar, outras vezes não se limitava de nenhum modo a criatividade dos pacientes.

No Grupo oficina de artes foram utilizadas técnicas de arteterapia e artesanato. Dentro desse grupo realizava-se também uma oficina de reciclagem. O objetivo principal era que os pacientes saíssem da instituição sabendo confeccionar objetos de uso pessoal (como bijuterias, bolsas etc.) e/ou decorativo (quadros, porta-retratos, tapetes etc.), bem como encadernaçôes e confecção de sabonetes, entre outros.

Durante o período de realização deste estudo (de julho a dezembro de 2010), um total de 280 pacientes foram internados na instituição, sendo 28 no mês de julho, 47 no mês de agosto, 49 em setembro, 53 em outubro, 45 em novembro e 58 em dezembro. Eram pacientes adultos e jovens adultos, faixa etária de 19 a 62 anos, sendo 182 (65,00\%) do gênero masculino e 98 (35,00\%), do feminino. Não foi possível caracterizar a escolaridade dos pacientes, pois muitos não apresentavam documentos e muitos, ainda, não tinham família que pudesse "comprovar" a sua condição. Para a internação na instituição era necessário somente a apresentaçáo de documento com foto (RG), do cartão SUS e de um comprovante de residência, além da autorização de internação hospitalar (AIH).

Como são variados os diagnósticos apresentados pelos pacientes, com o fim de facilitar o entendimento esses diagnósticos foram separados por categorias (de acordo com a Classificação Internacional de Doenças e Problemas relacionados à Saúde - CID10) (ORGANIZAÇÃO..., 2013), como: CID F19 (Transtornos mentais e comportamentais devido ao uso de múltiplas drogas e ao uso de outras substâncias); CID F20-29 (Esquizofrenia, transtorno esquizotípico e esquizoafetivo, transtornos delirantes persistentes e induzidos, transtornos psicóticos agudos 
e transitórios, outros transtornos psicóticos não orgânicos e psicose não orgânica não especificada); CID F30-39 (Episódio maníaco e depressivo, transtornos afetivos bipolares, transtornos depressivos recorrentes e transtornos do humor); e CID OUTROS (F10 - Transtornos mentais e comportamentais devido ao uso de álcool, F60 - Transtornos específicos da personalidade, F79 - Retardo mental não especificado e F80 - Transtornos específicos do desenvolvimento da fala e da linguagem). A Figura 1 apresenta a quantidade de pacientes internados no período do estudo $(\mathrm{n}=280)$, separados de acordo com o diagnóstico médico estabelecido.

De acordo com a Figura 1, observa-se uma prevalência de pacientes com diagnóstico das categorias F20-29 (46,07\%) e F30-39 (23,57\%), referentes aos quadros de esquizofrenia, transtornos psicóticos, psicoses, transtornos afetivos bipolares, episódios maníacos e depressivos, entre outros.

A frequência de realização dos grupos terapêuticos variava conforme a rotina da própria instituição, mas de modo geral era seguido um cronograma de atividades com a realização de dois grupos terapêuticos por dia, totalizando 10 grupos terapêuticos por semana e 40 no mês; entretanto, alguns meses apresentaram um número maior de grupos, como novembro (total de 56 grupos terapêuticos) e dezembro (total de 62 grupos terapêuticos). A participação total dos pacientes nos grupos e oficinas terapêuticas do setor de Terapia Ocupacional variava também conforme a quantidade de pacientes internados no dia, mas considerando-se que a média de internação nesse período de julho à dezembro de 2010 foi de 27 pacientes/dia, a participação máxima foi de 22 pacientes e a mínima de 17. A Figura 2 nos revela o total de participação dos pacientes, dispostos entre os diferentes grupos e oficinas terapêuticas, sendo que o mesmo paciente podia participar de mais de um grupo terapêutico.

Gráfico referente à quantidade de pacientes $(n=280)$ de acordo com os diagnósticos médicos
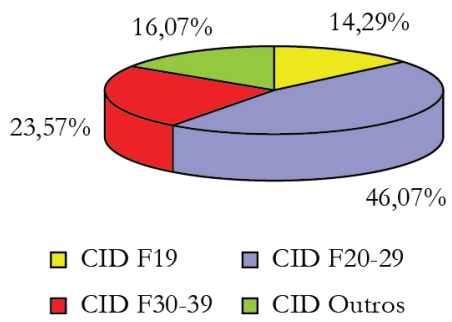

Figura 1. Quantidade de pacientes internados ( $\mathrm{n}=280)$ de acordo com o diagnóstico médico.
A Figura 2 nos revela que os pacientes participaram mais dos grupos operativos $(54,00 \%)$, seguidos dos grupos de reflexão $(52,85 \%)$, oficinas de artes (47,70\%) e oficinas de desenho (46,80\%).

$\mathrm{Na}$ literatura, alguns autores apontam a importância dos grupos reflexivos no tratamento de pacientes de saúde mental. Bezerra e Oliveira (2002) relatam que grupos terapêuticos (principalmente nos grupos de reflexão, em que o resultado final do trabalho do paciente relaciona-se a fatos já vividos) permitem retomar vivências durante um processo criativo, permitindo a reorganização emocional do paciente. De acordo com Munari (2004), através das atividades expressivas e de reflexão os pacientes encontram seu elo e caminho para a vida, mesmo que fora do padrão normal aceito pela sociedade.

Pacientes diagnosticados com CID F20-29 e F30-39 apresentaram participação maior nos grupos de reflexão, nos grupos operativos e nas oficinas de desenho. Nos grupos de reflexão, a participação do grupo CID F20-29 foi de 49,25\% e do grupo CID F30-39 foi de 24,25\%; nos grupos operativos, a participação dos pacientes com CID F20-29 foi de 54,00\% e dos pacientes com CID F30-39, de 27,00\%; e, nas oficinas de desenho, as participaçôes de pacientes de F20-29 e de F30-39 foram de 51,00\% e $22,00 \%$, respectivamente.

Nise da Silveira, no tratamento à pacientes esquizofrênicos, referiu aderência maior dos pacientes a atividades ditas "de livre expressão" (como atividades reflexivas, desenho, pintura, modelagem, entre outras), pois nessas atividades a atenção, a memória, as técnicas e até mesmo os pensamentos podem ficar temporariamente suspensos. Nise da Silveira apontou ainda que, no livre fazer, o curso das emoçôes, dos afetos e das lembranças e a lógica do pensamento não estão sendo exigidos podendo, ao contrário, estar sendo exercidos por cada paciente (CAVALCANTI; GALVÃO, 2007). Ferrari (2006) relatou que a diversidade de linguagens e formas

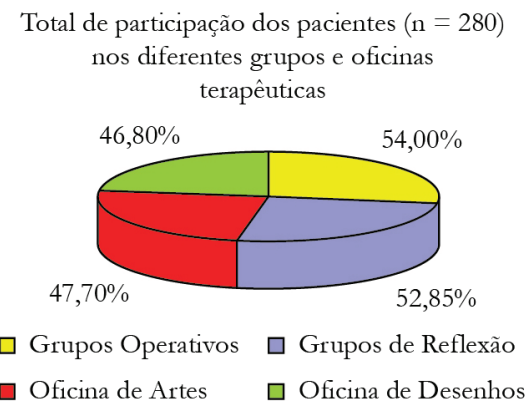

Figura 2. Porcentagem de pacientes $(\mathrm{n}=280)$ que participavam dos diferentes grupos e oficinas terapêuticas. 
de intervençáo oferecidas nos diferentes grupos e oficinas terapêuticas proporciona lugares que podem ser utilizados pelos pacientes para expressão, vivência e significação de conteúdos, entendido como necessário no tratamento desses pacientes.

Em relação à participação dos pacientes nas oficinas de artes, os resultados foram diferentes. Os dois grupos que se destacaram foram de pacientes pertencentes aos grupos CID F20-29 (com 66,00\% de participação) e CID F19 (com $43,50 \%$ de participação). Os pacientes que apresentavam quadros de transtornos mentais e comportamentais associados ao uso de múltiplas drogas e outras substâncias psicoativas (CID F19) neste estudo totalizavam 41 indivíduos (14,29\% do total de pacientes internados). Desses, alguns (27 pacientes, 65,85\%) já haviam sido internados em outras instituiçôes psiquiátricas e, também, submetidos a internaçôes compulsórias por ordem judicial, o que contribuiu para participarem com maior interesse das oficinas de artes, pois já estavam habituados, nos locais por onde passaram, a exercer atividades manuais como: jardinagem, horticultura e atividades que remetiam à sua sobrevivência na sociedade, como encadernaçáo, confecção de bijuterias, mosaicos, pintura em telas, entre outras. Conforme Brasil (2007), a política do Ministério da Saúde para a atenção integral aos usuários de álcool e drogas propóe que os novos equipamentos de saúde considerem o caráter multifatorial do consumo de drogas, realizando diálogos com serviços culturais, sociais e outras instituições de saúde e estruturando uma rede de assistência na atenção comunitária, com ênfase na reabilitação e reinserção social. Sendo assim, Oliveira et al. (2010) relatam que os Centros de Atenção Psicossocial de Álcool e Outras Drogas e outras instituiçóes especializadas no tratamento de dependentes químicos são considerados equipamentos estratégicos para essas novas práticas de saúde.

Durante o período do estudo, do total de pacientes internados ( $\mathrm{n}=280), 249(90,00 \%)$ obtiveram alta hospitalar no tempo predeterminado pela instituição (15 a 20 dias). Desses, 200 pacientes (80,32\%) participaram dos grupos terapêuticos propostos pelo setor de Terapia Ocupacional, sendo essa participação quantificada somente quando o paciente participava mais de cinco vezes durante o seu período de internação. Já os pacientes que não aderiram aos grupos e oficinas terapêuticas $(10,00 \%)$ obtiveram alta da instituiçâo em um período maior do que o estabelecido pela própria instituição; alguns pacientes $(16,06 \%)$ permaneceram até mais de 30 dias além da internação predeterminada. As taxas de reinternação $(4,00 \%)$ também se referiam a pacientes que náo aderiram aos grupos e oficinas terapêuticas. Pacientes que tiveram uma participação significativa (mais de cinco vezes) nos grupos terapêuticos não se reinternaram na instituição durante o período do estudo. É claro que quando se trata de pacientes de saúde mental, alguns ainda com quadro clínico crônico, as reinternaçôes são inevitáveis, principalmente nessa instituição específica, a única de internação intensiva que atende todos os municípios da Baixada Santista. Este estudo tentou mostrar a importância dos grupos terapêuticos da Terapia Ocupacional e sua contribuição para a alta hospitalar dos pacientes internados, mostrando que aqueles que aderiram aos grupos terapêuticos não apresentaram "recaída" (reinternação) em período curto de tempo,mantendo-se razoavelmente bem e convivendo em sociedade por intervalos mais longos.

\section{Conclusões}

Os pacientes com CID F20-29 e CID F30-39 apresentaram maior participação nos grupos em que foram discutidos conteúdos e emoções variadas, como: ideias de morte, solidão, conquistas, idealizaçôes, dificuldades, entre outros conteúdos tratados nos grupos de reflexão e operativos. Esses pacientes conseguiram expressar-se através de sua própria criaçáo e uma vez que os resultados finais dessas criaçóes estavam relacionados a fatos já vividos por eles, conseguiram retomar essas vivências no próprio processo criativo, o que náo só permitiu a reorganização emocional do paciente como também contribuiu para maior organização e coerência do pensamento, melhorando o quadro clínico e "adaptando" o paciente à sociedade.

Os pacientes com CID F19 apresentaram maior participação nas oficinas de artes, fato que pode ser explicado pelo perfil deles, pois muitos já tinham estado em presídios e/ou internados em outros hospitais de longa permanência, instituiçôes nas quais aprenderam a exercer atividades manuais como forma de renda para a própria sobrevivência.

Os pacientes que participaram dos grupos terapêuticos apresentaram uma melhora significativa em seu quadro clínico, receberam alta hospitalar no período predeterminado pela instituição e retomaram suas atividades na sociedade. Embora os dados da pesquisa refiram-se ao período de julho a dezembro de 2010, até a data de aceite deste artigo os pacientes que participaram efetivamente dos grupos terapêuticos apresentaram uma taxa de reinternação menor do que os demais e alguns não voltaram à internação nessa mesma instituição.

Através dos dados apresentados pode-se concluir que os grupos terapêuticos são eficazes no tratamento 
de pacientes de saúde mental, uma vez que contribuem para a sua alta hospitalar, melhorando seu quadro clínico.

Este estudo ressalta a importância da clínica de Terapia Ocupacional através de grupos terapêuticos para pacientes de saúde mental. Pesquisas futuras devem aprofundar os assuntos nele abordados.

\section{Agradecimento}

A autora agradece a colaboração da terapeuta ocupacional do Pólo de Atenção Intensiva em Saúde Mental da Baixada Santista (PAI), Camila Molina Lucenti de Souza.

\section{Referências}

AZEVEDO, T.; DIMENSTEIN, M. O acompanhamento terapêutico no cuidado em saúde mental. Estudos e Pesquisas em Psicologia, Rio de Janeiro, v. 1, n. 3, p. 658-671, 2008.

BALLARIN, M. L. G. S. Algumas reflexões sobre grupos de atividades em terapia ocupacional. In: PADUA, E. M. M.; MAGALHÃES, L. V. Terapia ocupacional: teoria e prática. Campinas: Papirus, 2003. p. 63-76.

BARATA, D. A.; COCENAS, S. A.; KEBBE, L. M. Coordenação de grupos de terapia ocupacional em enfermaria psiquiátrica - relato de supervisão realizada com uma estagiária. Cadernos de Terapia Ocupacional da UFSCar, São Carlos, v. 18, n. 2, p. 181-190, 2010.

BEZERRA, D. B.; OLIVEIRA, J. M. A atividade artística como recurso terapêutico em saúde mental. Boletim da Saúde, Porto Alegre, v. 16, n. 2, p. 135-137, 2002.

BRASIL. Ministério da Saúde. Secretaria de Atenção á Saúde/DAPE. Saúde Mental no SUS: acesso ao tratamento e mudança do modelo de atenção. Brasília: Ministério da Saúde, 2007. Relatório de Gestáo 2003-2006.

CAVALCANTI, A.; GALVÃO, C. Terapia ocupacional: fundamentação \& prática. Rio de Janeiro: Guanabara Koogan, 2007.

CUNHA, A. C. F.; SANTOS, T. F. A utilização do grupo como recurso terapêutico no processo da terapia ocupacional com clientes com transtornos psicóticos: apontamentos bibliográficos. Cadernos de Terapia Ocupacional da UFSCar, São Carlos, v. 17, n. 2, p. 133-146, 2009.

FERRARI, S. M. L. Terapia Ocupacional: a clínica em uma instituição de saúde mental. Cadernos de Terapia Ocupacional da UFSCar, São Carlos, v. 14, n. 2, p. 122-127, 2006.
HAGEDORN, R. Ferramentas para a prática em terapia ocupacional: uma abordagem estruturada aos conhecimentos e processos centrais. Tradução de Melissa Tieko Muramoto. São Paulo: Rocca, 2007.

KEBBE, L. M.; SANTOS, T. F.; COCENAS, S. A. Etapas constitutivas de um grupo de atividades em um hospital dia psiquiátrico: relato de experiência. Cadernos de Terapia Ocupacional da UFSCar, Sáo Carlos, v. 18, n. 1, p. 77-84, 2010.

LIEBMANN, M. Exercicios de arte para grupos: um manual de temas, jogos e exercícios. 4. ed. São Paulo: Summus, 2000.

MAXIMINO, V. S. Grupos de atividades com pacientes psicóticos. São José dos Campos: Univap, 2001.

MENDONÇA, T. C. P. As oficinas na saúde mental: relato de uma experiência na internaçáo. Psicologia, Ciência e Profissão, Brasília, v. 25, n. 4, p. 626-653, 2005. http:// dx.doi.org/10.1590/S1414-98932005000400011

MUNARI, D. Arte, arteiros e artistas: uma reflexão a cerca da arte. In: VALLADARES, A. C. C. (Org.). Arteterapia no novo paradigma de atenção em saúde mental. São Paulo: Vetor, 2004. p. 76.

NASCIMENTO, V. P. et al. Grupo de leitura e produçáo de textos: uma intervenção da terapia ocupacional. Revista de Terapia Ocupacional da USP, São Paulo, v. 18, n. 1, p. 17-21, 2007. http://dx.doi.org/10.11606/issn.2238-6149. v18ilp17-21

OLIVEIRA, E. et al. Práticas assistenciais no Centro de Atençāo Psicossocial de Álcool, Tabaco e outras Drogas. Revista de Terapia Ocupacional da USP, São Paulo, v. 21, n. 3, p. 247-254, 2010. http://dx.doi.org/10.11606/ issn.2238-6149.v21i3p247-254

ORGANIZAÇĀO MUNDIAL DA SAÚDE - OMS. CID 10 Classificação Internacional de Doenças e Problemas relacionados à Saúde. São Paulo: OMS, 2013. cap. V Transtornos mentais e comportamentais. Disponível em: <http://www.cid10.com.br>. Acesso: 11 out. 2012.

SAMEA, M. O dispositivo grupal como intervenção. Revista de Terapia Ocupacional da USP, São Paulo, v. 19, n. 2, p. 85-90, 2008.

SCHERER, Z. A. P.; SCHERER, E. A. O doente mental crônico internado: uma revisão da literatura. Revista Latino-Americana de Enfermagem, Ribeirão Preto, v. 9, n. 4, p. 56-61, 2001. http://dx.doi.org/10.1590/ S0104-11692001000400010

VILLARES, C. C. Terapia ocupacional na esquizofrenia. In: SHIRAKAWA, I.; CHAVES, A. C.; MARI, J. A. O desafio da esquizofrenia. São Paulo: Lemos Editorial, 1998. p. 183-195.

ZIMERMAN, D. E. Fundamentos básicos das grupoterapias. 2. ed. Porto Alegre: ARTMED, 2000.

\section{Notas}

${ }^{1}$ Parte dos resultados aqui apresentados foram debatidos no XII Congresso Brasileiro de Terapia Ocupacional e IX Congresso Latino Americano de Terapia Ocupacional, na cidade de São Paulo, SP, em 2011. 